\title{
THE EFFECT OF CHANGES IN HYDROGEN ION CONCENTRATION ON THE PULMONARY CIRCULATION *
}

\author{
By EDWARD H. BERGOFSKY, $\dagger$ DAVID E. LEHR $\ddagger$ AND ALFRED P. FISHMAN
}

(From the Department of Medicine, Columbia University College of Physicians and Surgeons, and the Cardiorespiratory Laboratory of the Presbyterian Hospital, New York, N. Y.)

(Submitted for publication January 23, 1962; accepted March 22, 1962)

Although acidosis has long been known to cause vasodilation in certain systemic vascular beds (13 ), its effect on the pulmonary vessels remains unsettled. This uncertainty stems from the inconsistent effects of an acute change in blood $\mathrm{pH}$ on the pulmonary circulation of the isolated lung (4-8) and of the lung perfused in situ (9), and the lack of observations on intact animals and man.

Liljestrand, on the basis of experiments involving the exposure of the isolated lung to severe hypoxia, recently proposed that the release of lactic acid from the cells of the lung is responsible for the increase in pulmonary arterial pressure during acute hypoxia (10). However, it is not clear to what extent this hypothesis, based on the behavior of an artificial preparation during drastic experimental conditions, applies to the behavior of the normal pulmonary circulation of either the intact animal or man during less severe hypoxia.

The present study was designed to assess the role of acidosis in the regulation of the pulmonary circulation of intact animals and man. We found that acidosis can increase pulmonary vascular resistance. Experiments were then undertaken : 1) to distinguish between the effects of the hydrogen ion and the effects of the associated anions on the pulmonary circulation, and 2) to determine the role of acidosis in the pulmonary arterial pressor responses to acute hypoxia and to acute hypercapnia.

\section{SUBJECTS AND METHODS}

Acute acidosis. In order to avoid the increase in minute ventilation which acidosis evokes in unanesthetized

* Supported in part by Grant H-2299 (C3) from the National Heart Institute, with additional support from the American Heart Association and the New York Heart Association. Presented in part at the Conference on In-Vitro and In-Vivo Effects of Amine Buffers, The New York Academy of Sciences, December 12, 1960.

+ Senior Fellow of the New York Heart Association. $¥$ Fellow of the American Trudeau Society. animals and man, and which prevents large changes in the blood $\mathrm{pH}$, the effects of acidosis were studied during controlled ventilation in anesthetized dogs. Eleven dogs were anesthetized with intravenous pentobarbital (Nembutal), $30 \mathrm{mg}$ per $\mathrm{kg}$. The minute ventilation was controlled by means of an automatic, intermittent, positive pressure breathing apparatus (Bird), connected to the trachea of the dog by means of a cuffed endotracheal tube. The breathing apparatus was incorporated into an open circuit in such a way that expired air could be collected in a gasometer. In each dog a no. 6 cardiac catheter was introduced into the pulmonary artery under fluoroscopic control by way of a jugular vein. An indwelling needle was placed in one femoral artery; a no. 6 cardiac catheter was threaded retrogradely, through the other femoral artery, into the left ventricle.

The experiments were of three types: a comparison of the effects of lactic acid with those of hydrochloric acid (four dogs); a comparison of the effects of lactic acid with those of acute hypercarpnia (three dogs); and the effects of lactic acid during acute hypoxia (four dogs).

Each type of experiment consisted of four periods; each period lasted for 15 to 20 minutes. The first type of experiment, involving the comparison of the effects of lactic with hydrochloric acid, consisted of the following periods: 1) control, i.e., ambient air breathing during the intravenous infusion of normal saline at a rate of $4 \mathrm{ml}$ per minute; 2) the infusion of $0.3 \mathrm{M}$ lactic acid at the same rate; 3) repeat control, 30 minutes after the second period, when the arterial blood $\mathrm{pH}$ had returned toward normal; and 4) the infusion of $0.3 \mathrm{M}$ hydrochloric acid at the same rate. The second type of experiment, which compared the effects of lactic acid and acute hypercapnia, was the same as the first, except for the fourth period, when an inspired mixture containing 5 per cent $\mathrm{CO}_{2}$ in air was substituted for ambient air, and normal saline was infused at the standard rate of $4 \mathrm{ml}$ per minute. For the third type of experiment, which tested the effects of acute acidosis during acute hypoxia, the first two periods were the same as the first two periods of the previous experiments; during the third period, an inspired mixture of 12 per cent $\mathrm{O}_{2}$ in $\mathrm{N}_{2}$ was substituted for ambient air; during the fourth period, an infusion of $0.3 \mathrm{M}$ lactic acid, at the rate of $4 \mathrm{ml}$ per min, was substituted for the normal saline as the dog continued to breathe the hypoxic inspired mixture.

Blood pressures were recorded, at different paper speeds, either continuously or at 1-minute intervals. For the sake of precise measurement, records of diastolic blood 


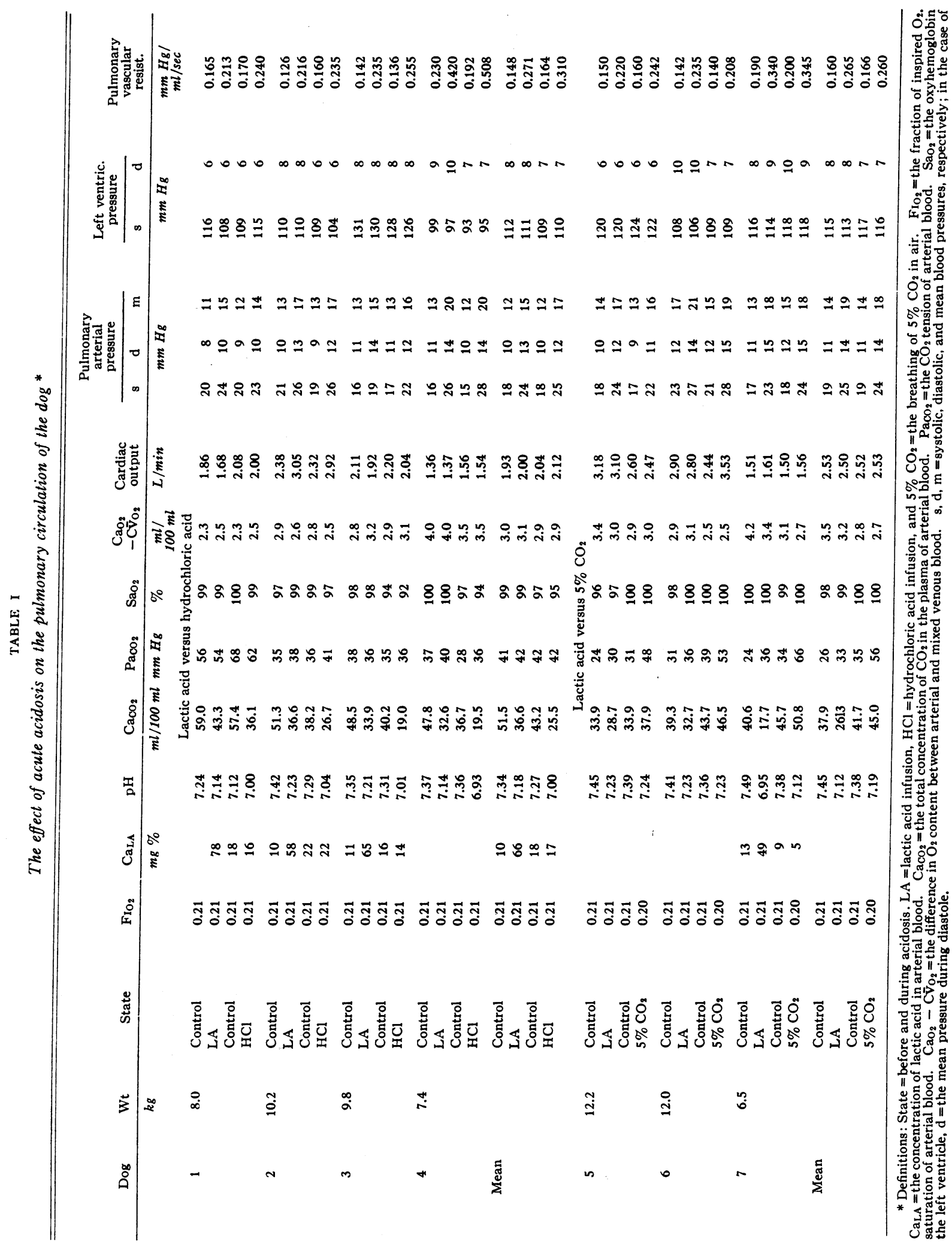


pressures in the left ventricle were taken, in rapid succession, at several different gains. Expired gas for the calculation of the oxygen uptake and the respiratory exchange ratio was collected in a 13-L spirometer during the final 2 minutes of each period; blood samples were drawn simultaneously from the brachial and pulmonary arteries during the middle minute of gas collection for the determination by the Fick principle of the cardiac output.

Acute alkalosis. The effects of acute alkalosis in modifying the pulmonary arterial pressor response to acute hypoxia were studied in unanesthetized normal human subjects. The subjects were six men and three women, ranging in age from 17 to 47 years. All studies were performed in the morning after an overnight fast. An indwelling needle was inserted into the brachial artery and a no. 8 cardiac catheter was passed from the antebrachial vein into the pulmonary artery (11). An opencircuit breathing system was used to deliver either ambient air or the hypoxic gas and to collect expired air in a 120-L gasometer. Each study consisted of four periods: 1) control, ambient air breathing; 2) acute hypoxia, during which an inspired mixture of 12 per cent $\mathrm{O}_{2}$ in $\mathrm{N}_{2}$ was substituted for ambient air ; 3) ambient air breathing plus alkali; and 4) acute hypoxia plus alkali. Throughout each study an infusion of fluid was continued at the rate of $6 \mathrm{ml}$ per minute: in five subjects normal saline was infused until 25 minutes before the start of period 3 when a solution of $0.3 \mathrm{M}$ Tris was substituted for the saline; in four other subjects a solution of $0.3 \mathrm{M}$ sodium bicarbonate was substituted for the saline. During periods 2 and 4 the hypoxic inspired gas mixture was administered for the last 15 to 20 minutes of the period. As in the animal experiments, the appropriate blood and gas samples were collected during the final 2 minutes of each period.

Analytic techniques and calculations. The same analytic techniques were used in both sets of experiments. Blood pressures were recorded from the intracardiac catheters by strain gauges and an oscilloscope recorder (Electronics for Medicine). Cardiac output was measured by the Fick principle during a steady state of respiration and circulation (12). The $\mathrm{O}_{2}$ and $\mathrm{CO}_{2}$ contents of expired air were measured by the micro-Scholander technique (13), and the $\mathrm{O}_{2}$ and $\mathrm{CO}_{2}$ contents of mixed venous and arterial blood were analyzed by the method of Van Slyke and Neill (14). The blood $\mathrm{pH}$ was measured at $37^{\circ} \mathrm{C}$ (McInnes-Belcher glass electrode). The concentration of lactic acid in arterial blood was determined by the method of Barker and Summerson (15).

The arterial $\mathrm{CO}_{2}$ tension was calculated from the $\mathrm{pH}$ and the $\mathrm{CO}_{2}$ content of serum, by use of the line charts of Van Slyke and Sendroy (16). The pulmonary. vascular resistance was calculated as the ratio of mean pulmonary arterial pressure minus mean left ventricular diastolic pressure to the cardiac output.

For the 22 experimental periods involving acidosis, the constants in the best linear equations relating pulmonary vascular resistance to arterial blood $\mathrm{pH}$, on the one hand. and to arterial blood $\mathrm{Pco}_{\text {, }}$, on the other, were calculated by the method of least squares; their significance was estimated by the Fisher $t$ test. Similar statistical analyses were performed for the relationship between pulmonary vascular resistance and arterial blood $\mathrm{pH}$ produced by the infusion of lactic acid, the infusion of hydrochloric acid, and the breathing of $\mathrm{CO}_{2}$, respectively.

\section{RESULTS}

\section{Acute acidosis}

Lactic acid versus hydrochloric acid. The effects of these acids on the pulmonary circulation of four dogs are compared in Table I. It may be seen that the infusion of $\mathrm{HCl}$ effected a slightly greater decrement in arterial $\mathrm{pH}$ than did the infusion of lactic acid $(-0.27$ as compared with $-0.16)$. The concentration of lactic acid in the arterial blood increased five- to sixfold during the lactic acid infusion but remained at control levels during the infusion of hydrochloric acid. Despite these dissimilarities in the concentrations of anions (i.e., lactate versus chloride) in the pulmonary arterial pressure increased in each animal during acidosis. The average increases were $3 \mathrm{~mm} \mathrm{Hg}$ during the lactic acid infusion and $5 \mathrm{~mm} \mathrm{Hg}$ during the $\mathrm{HCl}$ infusion. The most striking changes in pulmonary arterial pressure occurred in dog 4, which also had the most marked changes in arterial $\mathrm{pH}$. These consistent changes in pulmonary arterial pressure occurred in the face of unchanged left ventricular pressure in all dogs and of unchanged cardiac output in three of the four dogs; in the fourth animal $(\operatorname{dog} 2)$, the cardiac output increased by equal amounts during the two periods of acidosis.

The changes in calculated pulmonary vascular resistance that occurred during the infusion of the acids is illustrated for each animal in the upper half of Figure 1. It can be seen in each animal that acidosis was associated with an increase in calculated resistance. Moreover, the slopes of the lines relating arterial $\mathrm{pH}$ to resistance were similar for the two acids.

Lactic acid versus 5 per cent $\mathrm{CO}_{2}$. The effects of infusing lactic acid and of controlled ventilation with 5 per cent $\mathrm{CO}_{2}$ in air are compared in the middle portion of Table I. The two acids had different effects on the composition of arterial blood. 1) The degree of acidosis produced by the infusion of lactic acid exceeded that produced by $\mathrm{CO}_{2}$ breathing ; thus, the average decrement in arterial $\mathrm{pH}$ was 0.33 during the infusion of lactic 
acid and 0.19 during $\mathrm{CO}_{2}$ breathing. 2) During $\mathrm{CO}_{2}$ breathing the $\mathrm{CO}_{2}$ content of arterial serum increased, on the average, by $4 \mathrm{ml}$ per $100 \mathrm{ml}$ and the $\mathrm{P}_{\mathrm{CO}_{2}}$ increased by $21 \mathrm{~mm} \mathrm{Hg}$; in contrast, the arterial $\mathrm{CO}_{2}$ content fell by approximately $11 \mathrm{ml}$ per $100 \mathrm{ml}$ during the lactic acid infusion and the $\mathrm{P}_{\mathrm{CO}_{2}}$ increased by only $4 \mathrm{~mm} \mathrm{Hg}$. 3) The concentration of lactate in the arterial blood increased markedly during the infusion of lactic acid but remained unchanged during $\mathrm{CO}_{2}$ breathing. Despite these differences, each dog responded to both the infusion of lactic acid and to the breathing of the $\mathrm{CO}_{2}$ mixture with a rise in pulmonary arterial pressure. The increases in pulmonary arterial pressure were not associated with changes in either the cardiac output or left ventricular pressure. Finally, the lower half of Figure 1 shows that, despite the considerable differences between the concentration of the anions in the arterial blood, similar decrements in arterial $\mathrm{pH}$ were associated with equivalent increments in mean pulmonary vascular resistance.

Lactic acid during acute hypoxia. The effects of infusing lactic acid during acute hypoxia are
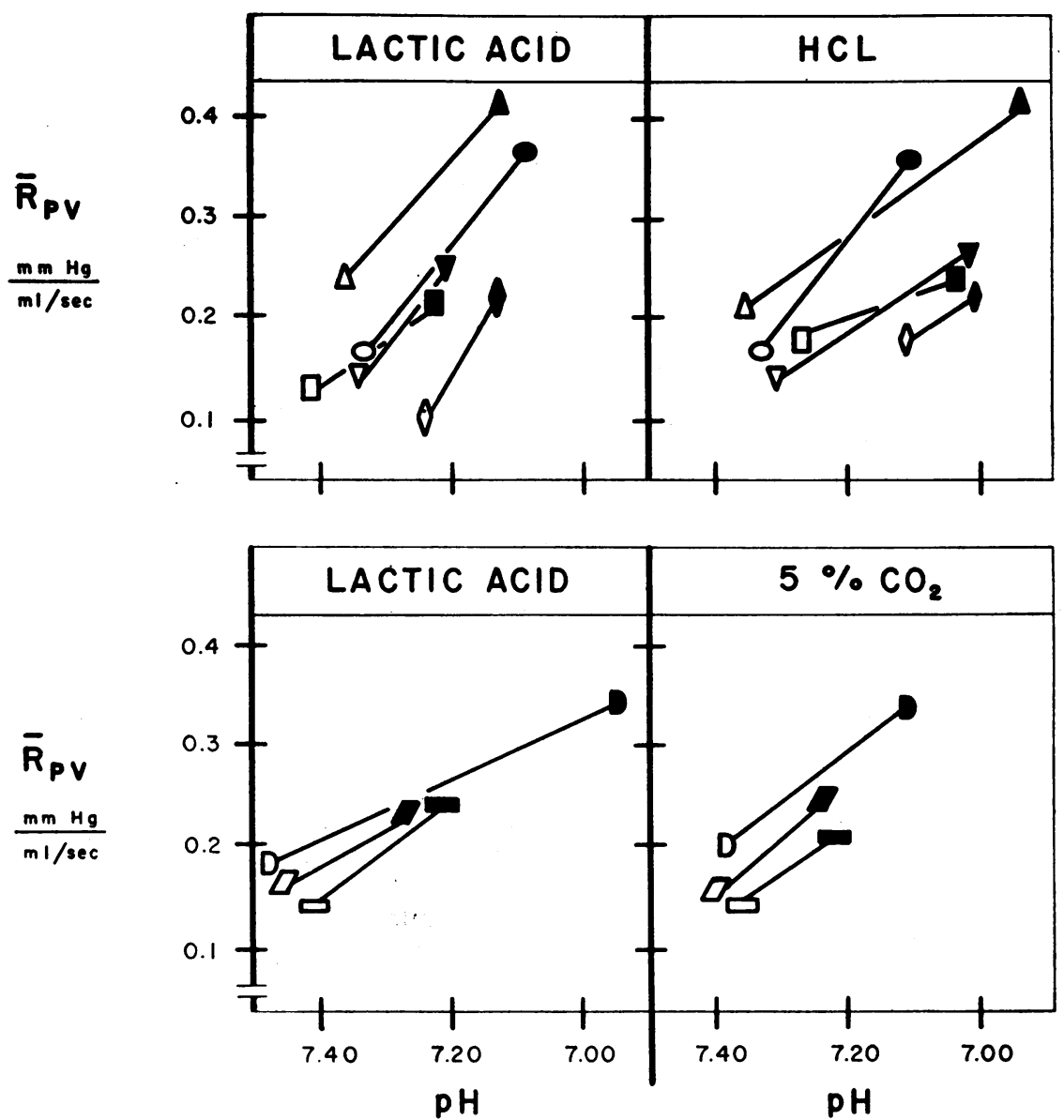

Fig. 1. The effects of a change in PH on mean pulmonary vascular RESISTANCE ( $\overline{R P V}$ ) IN THE DOG. Upper half: The effects in the same animals of infusions of $0.3 \mathrm{M}$ lactic acid and $0.3 \mathrm{M}$ hydrochloric acid. Lower half: The effects in another group of animals of infusing $0.3 \mathrm{M}$ lactic acid and of breathing 5 per cent $\mathrm{CO}_{2}$.

Each symbol represents a single animal: the open symbols represent control values before the acidosis; the solid symbols represent the corresponding values during acidosis. Equal decrements in $\mathrm{pH}$ evoke similar increments in pulmonary vascular resistance, regardless of the acidifying agent. 


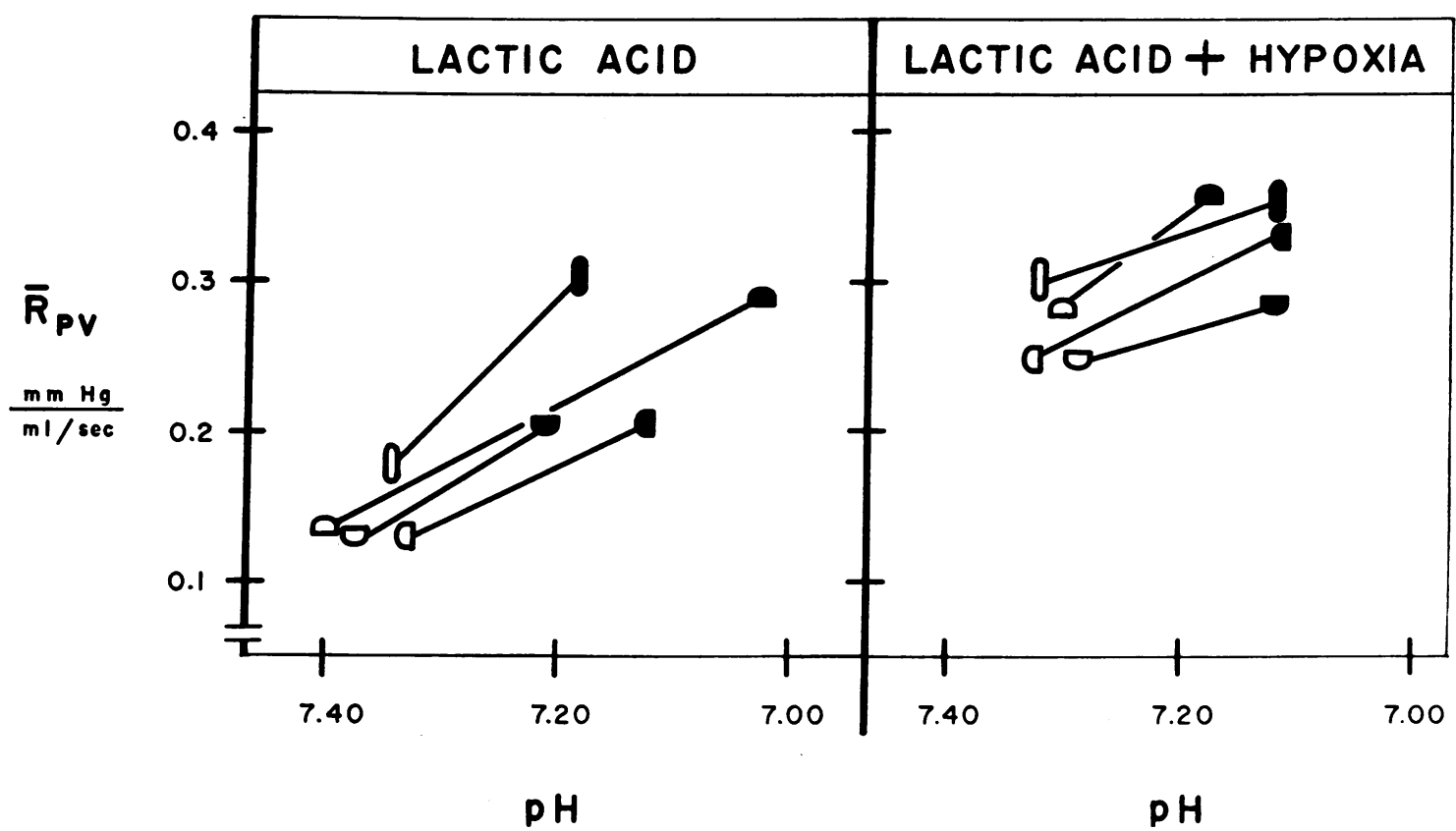

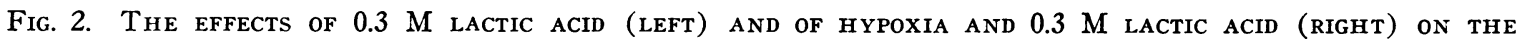
PULMONARY VASCULAR RESISTANCE OF FOUR DOGS. As in Figure 1, each symbol represents an individual animal. For equivalent decreases in $\mathrm{pH}$, an infusion of lactic acid produces the same increase in pulmonary vascular resistance during ambient air breathing as during the breathing of 12 per cent $\mathrm{O}_{2}$ in $\mathrm{N}_{2}$.

itemized for four dogs in the bottom portion of Table I. In these animals the infusion of lactic acid during ambient air breathing was associated with an average increase in pulmonary arterial pressure of $4 \mathrm{~mm} \mathrm{Hg}$. Acute hypoxia elicited an approximately equal increase; the infusion of lactic acid during acute hypoxia evoked a further increase of $3 \mathrm{~mm} \mathrm{Hg}$. The change in pulmonary vascular resistance that accompanies lactic acidemia during ambient breathing is compared with the change evoked by lactic acidemia during acute hypoxia in Figure 2. It may be seen that in each dog, lactic acidemia without hypoxia (left panel) elicited an increase in resistance corresponding to that previously observed in the first seven dogs of Table I. The substitution of the hypoxic inspired mixture for ambient air (right panel) elicited a further increase in resistance. The increment in resistance per unit decrement in arterial $\mathrm{pH}$ was similar, however, during ambient air breathing and during acute hypoxia.

Statistical analysis of data. The increase in pulmonary vascular resistance during the 22 periods of acidosis in the 11 dogs is statistically significant $(\mathrm{SE}=0.019 ; \mathrm{p}<0.01)$. Moreover, a statistically significant relationship exists between the increments in pulmonary vascular resistance $\left(\bar{R}_{p}\right)$ and the decrements in arterial blood $\mathrm{pH}\left(\Delta \overline{\mathrm{R}}_{\mathrm{p}}=-\right.$ $0.047+0.686 \cdot \Delta \mathrm{pH} ; \mathrm{p}<0.01)$. With respect to the individual acidifying agents, the relationship between the pulmonary vascular resistance and the decreases in arterial blood $\mathrm{pH}$ is statistically significant for lactic acid experiments $\left(\Delta \overline{\mathrm{R}}_{\mathrm{p}}=0.1095\right.$ $+0.201 \cdot \Delta \mathrm{pH} ; \mathrm{p}<0.01)$ and probably significant for the $\mathrm{CO}_{2}$ experiments $\left(\Delta \overline{\mathrm{R}}_{\mathrm{p}}=-0.006+0.581\right.$. $\Delta \mathrm{pH} ; \mathrm{p}<0.05)$ and for the $\mathrm{HCl}$ experiments $\left(\Delta \mathrm{R}_{\mathrm{p}}=-0.074+0.796 \cdot \Delta \mathrm{pH} ; \mathrm{p}<0.05\right)$.

A statistically significant increase in arterial blood $\mathrm{P}_{\mathrm{CO}_{2}}$ occurred during the 22 periods of acidosis $(\mathrm{SE}=1.74 ; \mathrm{p}<0.01)$. However, in contrast to the statistically significant relationship between $\overline{\mathrm{R}}_{\mathbf{p}}$ and $\mathrm{pH}$ in these animals, the linear equation relating increases in pulmonary vascular resistance to increases in arterial blood $\mathrm{P}_{\mathrm{CO}_{2}}$ has no appreciable slope $\left(\Delta \bar{R}_{p}=0.104+0.00022\right.$. $\left.\Delta \mathrm{P}_{\mathrm{CO}_{2}}\right)$.

\section{Acute alkalosis}

Amine buffer. The effects of Tris in modifying the changes induced by acute hypoxia on the com- 


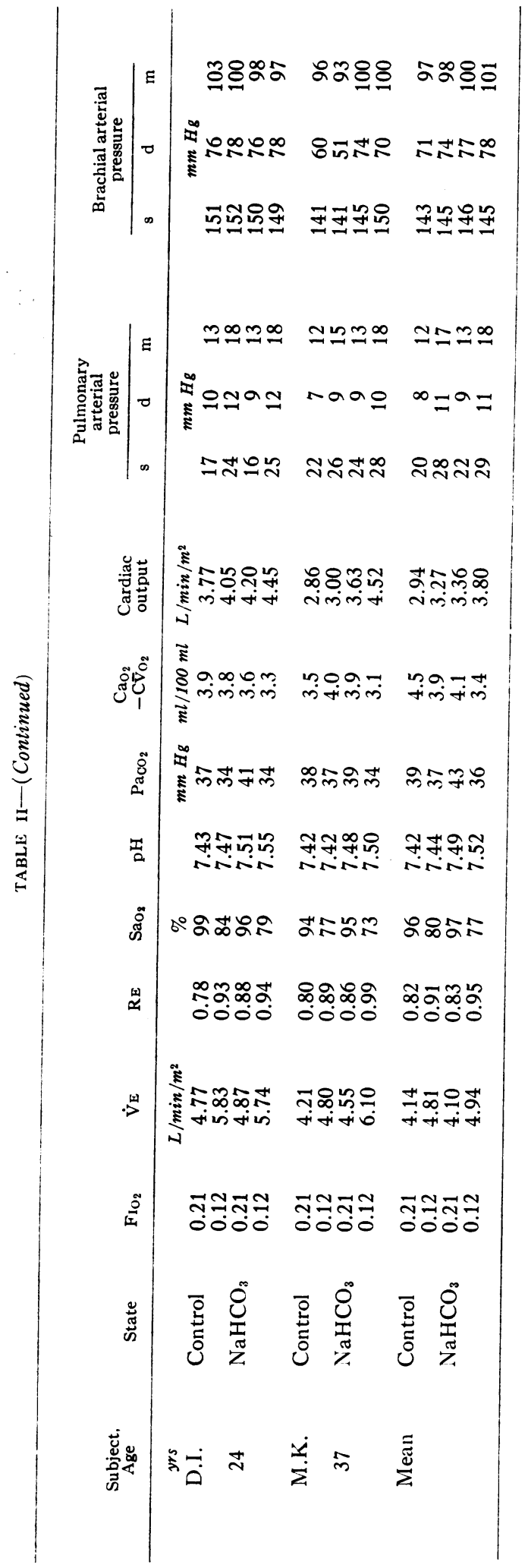

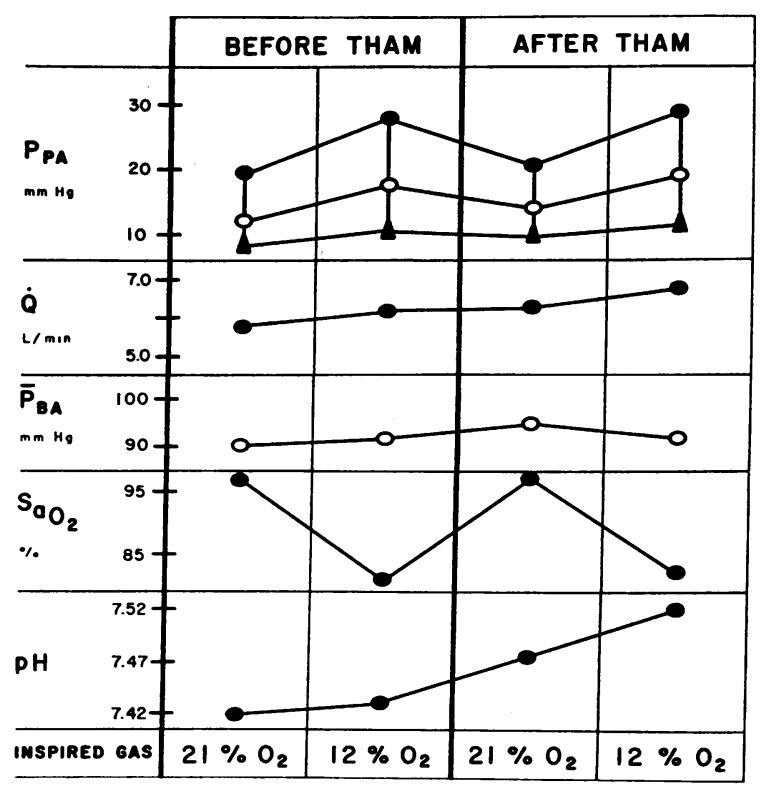

Fig. 3. The AVERAge PUlmonary hemodynamic EFFECTS OF $0.3 \mathrm{M}$ THAM (TRIS) DURING AMBIENT AIR BREATHING AND DURING HYPOXIA IN FIVE NORMAL HUMAN SUBJECTS. The pulmonary arterial pressure $\left(P_{P_{A}}\right)$ is represented by solid circles for systolic values, open circles for mean values, and triangles for diastolic values; $\overline{\mathbf{P}}_{\mathrm{BA}}$ refers to the mean brachial arterial pressure, $\dot{Q}$, to cardiac output and $\mathrm{Sa}_{2}$ to arterial $\mathrm{O}_{2}$ saturation. The pulmonary hemodynamic response to acute hypoxia is the same before and during the infusion of Tris.

position of arterial blood, the pulmonary circulation, and the systemic blood pressure are summarized for each of the five human subjects in the upper portion of Table II. Despite the alkalosis induced by Tris, the changes in arterial oxygen saturation and $\mathrm{CO}_{2}$ tension during acute hypoxia were approximately the same before and after the infusion of the buffer. Figure 3 summarizes the average effects of acute hypoxia on the circulation before and after the infusion of Tris. It may be seen that both the $\mathrm{pH}$ and the cardiac output continued to increase during the course of the experiments. Nonetheless, the magnitude and the pattern of change of the pulmonary arterial pressure were unaffected by the infusions. The brachial arterial pressure remained virtually unchanged during the consecutive periods.

Sodium bicarbonate. The experiments involving the use of sodium bicarbonate instead of Tris are detailed for the four human subjects in the lower half of Table II. The degrees of hypoxemia 


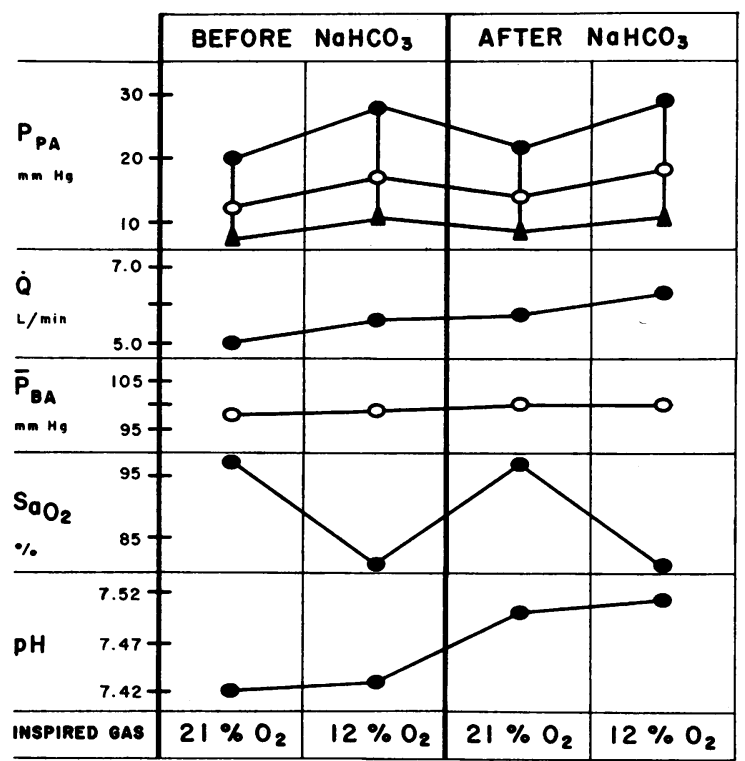

Fig. 4. The average PULMONARY hemodynamic EFFECTS OF $0.3 \mathrm{M}$ SODIUM BICARBONATE DURING AMBIENT AIR BREATHING AND DURING HYPOXIA IN FOUR NORMAL Humans. Symbols as in Figure 3. The pulmonary arterial pressor response to hypoxia is the same before and during the infusion of sodium bicarbonate.

and alkalosis were virtually identical in the Tris and the bicarbonate experiments. The effects of the two alkalinizing agents on the cardiac output were also similar. Finally, as may be seen in Figure 4 , the infusion of sodium bicarbonate, just as the infusion of Tris, did not modify the pulmonary arterial pressor response to acute hypoxia.

\section{DISCUSSION}

The present study has shown that acute acidosis in the anesthetized dog elicits an increase in pulmonary arterial pressure without affecting either the pulmonary blood flow or the blood pressures in the left ventricle; the magnitude of the pulmonary arterial pressor response to acidosis is related to the change in the blood $\mathrm{pH}$, rather than to associated anions of the acids; and acute alkalosis in unanesthetized human subjects does not modify the pulmonary arterial pressor response to hypoxia. These results have two major implications: acute acidosis elicits pulmonary vasoconstriction, and acute acidosis is not involved in the pulmonary vasoconstriction of acute hypoxia.

These experiments also seem to provide a reasonable explanation of the variable effects which
$\mathrm{CO}_{2}$ breathing is reported to exert on the pulmonary circulation $(17,18)$. Thus, according to the present study, both the infusion of fixed acids and the breathing of $\mathrm{CO}_{2}$ elicited the same rise in pulmonary arterial pressure for equivalent decreases in blood $\mathrm{pH}$, even though the increments in blood $\mathrm{P}_{\mathrm{CO}_{2}}$ were very small during the acid infusions and very large during the $\mathrm{CO}_{2}$ breathing. These observations suggest that at least some of the reported variability in the effects of $\mathrm{CO}_{2}$ breathing on the pulmonary circulation may be attributable to the different degrees of acidosis which $\mathrm{CO}_{2}$ breathing evokes under different experimental conditions: in normal unanesthetized human subjects, a "compensatory" increase in minute ventilation minimizes the change in blood $\mathrm{pH}$ so that $\mathrm{CO}_{2}$ breathing is without discernible effect on the pulmonary circulation (17); by way of contrast, when ventilation is controlled so that drastic changes in blood $\mathrm{pH}$ can occur, $\mathrm{CO}_{2}$ breathing may elicit appreciable increments in pulmonary vascular resistance.

The present experiments also suggest that the effect of a change in blood $\mathrm{pH}$ on the pulmonary circulation originates in extracellular, rather than in intracellular acidosis. This conclusion is based on the observation that $\mathrm{CO}_{2}$ penetrates cells more rapidly than does the hydrogen ion $(19,20)$; consequently, during experimental periods of only 20 minutes, a comparable degree of extracellular acidosis is apt to be associated with a greater degree of intracellular acidosis during $\mathrm{CO}_{2}$ breathing than during the infusion of fixed acids. The consistent relationship between the change in pulmonary arterial pressure and the change in arterial blood $\mathrm{pH}$, regardless of the acidifying agent, suggests that the mechanism for vasoconstriction in acidosis originates from without the cell.

On the basis of experiences with severe hypoxia in the isolated lung, Liljestrand proposed that the intrapulmonary release of lactic acid is responsible for the pulmonary pressor response to hypoxia (10). However, in both the intact animal and man, acute hypoxia characteristically elicits respiratory alkalosis as well as pulmonary hypertension; it does not evoke lactic acidemia (21). Therefore, the application of Liljestrand's hypothesis to the intact animal presupposes that the lactic acid is produced within the vascular smoothmuscle cells, but is released in quantities too small 
either to be detected in the blood stream or to affect the blood $\mathrm{pH}$. The use of the amine buffer to test this possibility is based upon three considerations: 1) the pulmonary vascular cells, like other cells, have poorer buffering capacity than has extracellular fluid $(22) ; 2$ ) the amine buffer accumulates rapidly in cells (23) so that intracellular $\mathrm{pH}$ may be expected to increase more than does extracellular $\mathrm{pH}(24)$; and 3 ) the $\mathrm{pK}_{\mathrm{a}}$ of the amine buffer (6.10) is such that it should serve as an efficient neutralizer of released acid (25) over the usual range of intracellular or extracellular $\mathrm{pH}$ (6.5 to 7.5). When viewed with respect to the extracellular alkalosis and the lack of lactic acidemia, the failure of the amine buffer to modify the pulmonary arterial pressor response to hypoxia suggests that neither intracellular nor extracellular lactic acidosis is involved in the pulmonary pressor response to hypoxia.

\section{SUM MARY}

1. The present study was concerned with the role of the hydrogen ion in the regulation of the pulmonary circulation.

2. We found that acute acidosis of sufficient degree, whether induced by infusion of fixed acids or breathing carbon dioxide, consistently elicits an increase in pulmonary arterial pressure which is, in turn, attributable to pulmonary vasoconstriction.

3 . The consistent relationship between the degree of acidosis and the increase in pulmonary vascular resistance, regardless of the acidifying agent, indicates that the hydrogen ion, rather than the associated anions of the acids, is involved in the pulmonary vasoconstriction.

4. These experiences with acute acidosis in dogs and acute alkalosis in man are relevant to the role of the hydrogen ion in the pulmonary arterial pressor responses to acute hypercapnia and acute hypoxia; whereas acute hypercapnia seems to elicit pulmonary vasoconstriction through the acidosis it produces, acute hypoxia appears to be an independent stimulus to pulmonary vasoconstriction.

\section{REFERENCES}

1. Gaskell, W. H. On the tonicity of the heart and blood vessels. J. Physiol. (Lond.) 1880, 3, 48.

2. Deal, C. P., Jr., and Green, H. D. Effects of $\mathrm{pH}$ on blood flow and peripheral resistance in muscular and cutaneous beds in the hind limb of the pentobarbitalized dog. Circulat. Res. 1954, 2, 148.

3. Kester, N. C., Richardson, A. W., and Green, H. D. Effect of controlled hydrogen-ion concentration on peripheral vascular tone and blood flow in innervated hind leg of the dog. Amer. J. Physiol. 1952, 169, 678.

4. Nisell, O. Effects of oxygen and carbon dioxide on the circulation of isolated and perfused lungs of the cat. Acta physiol. scand. 1948, 16, 121.

5. Nisell, $O$. The influence of blood gases on the pulmonary vessels of the cat. Acta physiol. scand. 1951, 23, 85.

6. Duke, H. N. Pulmonary vasomotor responses of isolated perfused cat lungs to anoxia and hypercapnia. Quart. J. exp. Physiol. 1951, 36, 75.

7. Duke, H. N. Observations on the effects of hypoxia on the pulmonary vascular bed. J. Physiol. (Lond.) 1957, 135, 45.

8. Duke, H. N., Killick, E. M., and Marchant, J. V. Changes in $\mathrm{pH}$ of the perfusate during hypoxia in isolated perfused cat lungs. J. Physiol. (Lond.) 1960, 153, 413.

9. Weil, P., Salisbury, P. F., and State, D. Physiological factors influencing pulmonary artery pressure during separate perfusion of the systemic and pulmonary circulations in the dog. Amer. J. Physiol. 1957, 191, 453.

10. Liljestrand, G. Chemical control of the distribution of pulmonary blood flow. Acta physiol. scand. 1958, 14, 120.

11. Bloomfield, R. A., Lauson, H. D., Cournand, A., Breed, E. S., and Richards, D. W. Recording of right heart pressures in normal subjects and in patients with chronic pulmonary disease and various types of cardio-circulatory disease. J. clin. Invest. 1946, 25, 639.

12. Fishman, A. P., McClement, J., Himmelstein, A., and Cournand, A. Effects of acute anoxia on the circulation and respiration in patients with chronic pulmonary disease studied during the "steady state." J. clin. Invest. 1952, 31, 770.

13. Scholander, P. F. Analyzer for accurate estimation of respiratory gases in one-half cubic centimeter samples. J. biol. Chem. 1947, 167, 235.

14. Van Slyke, D. D., and Neill, J. M. The determination of gases in blood and other solutions by vacuum extraction and manometric measurement. I. J. biol. Chem. 1924, 61, 523.

15. Barker, S. B., and Summerson, W. H. The colorimetric determination of lactic acid in biological material. J. biol. Chem. 1941, 138, 535.

16. Van Slyke, D. D., and Sendroy, J., Jr. Studies of gas and electrolyte equilibria in blood. XV. Line charts for graphic calculations by Henderson-Hasselbalch equation, and for calculating plasma carbon dioxide content from whole blood content. J. biol. Chem. 1928, 79, 781. 
17. Fishman, A. P., Fritts, H. W., Jr., and Cournand, A. Effects of breathing carbon dioxide upon the pulmonary circulation. Circulation 1960, 22, 220.

18. Fishman, A. P. Respiratory gases in the regulation of the pulmonary circulation. Physiol. Rev. 1961, 41, 214.

19. Gesell, R., Kreuger, H., Gorham, G., and Bernthal, T. The regulation of respiration. A study of the correlation of numerous factors of respiratory control following intravenous injection of sodium bicarbonate. Amer. J. Physiol. 1930, 94, 387.

20. Robin, E. D., Whaley, R. D., Crump, C. H., Bickelman, A. G., and Travis, D. M. Acid-base relations between spinal fluid and arterial blood with special reference to control of ventilation. J. appl. Physiol. 1958, 13, 385.
21. Huckabee, W. E. Relationships of pyruvate and lactate during anaerobic metabolism. III. Effects of breathing low-oxygen gases. J. clin. Invest. 1958, 37, 264.

22. Fenn, W. O. $\mathrm{CO}_{2}$ and intracellular homeostasis. Ann. N. Y. Acad. Sci. 1961, 92, 547.

23. Holmdahl, M. H., and Nahas, G. .G. Volume of distribution of $\mathrm{C}^{14}$ tagged 2-amino-2-hydroxymethyl1,3-propanediol (THAM). Fed. Proc. 1961, 20, $75 \mathrm{e}$.

24. Robin, E. D. Intracellular acid-base relations and intracellular buffers. Ann. N. Y. Acad. Sci. 1961, 92, 539.

25. Ligou, J. C., and Nahas, G. G. Comparative effects of acidosis induced by acid infusion and $\mathrm{CO}_{2}$ accumulation. Amer. J. Physiol. 1960, 198, 1201. 